\title{
HÍBRIDOS EXPERIMENTAIS DE MELÃO RENDILHADO CULTIVADOS EM SOLO E SUBSTRATO ${ }^{1}$
}

\author{
HAMILTON CÉSAR DE OLIVEIRA CHARLO², FRANCINE DE SOUZA GALATTI ${ }^{3}$, \\ LEILA TREVIZAN BRAZ4 ${ }^{4}$ JOSÉ CARLOS BARBOSA ${ }^{5}$
}

RESUMO- Este trabalho teve como objetivo verificar o desempenho de híbridos experimentais de melão rendilhado em dois sistemas de cultivo. Foram avaliados seis híbridos experimentais (Jab 07\#16, Jab 07\#17, Jab 07\#23, Jab 07\#24, Jab 07\#26, Jab 07\#28) e três híbridos comerciais (Bônus nº 2, Louis e Fantasy), em dois sistemas de cultivo (em solo e em fibra da casca de coco). O delineamento experimental utilizado foi em blocos casualizados, com nove tratamentos e quatro repetições, para cada experimento, realizando-se análise conjunta dos dados. Foram avaliados: massa média do fruto; produtividade; diâmetro médio transversal do fruto; diâmetro médio longitudinal do fruto; índice de formato de fruto; diâmetro médio transversal do lóculo; diâmetro médio longitudinal do lóculo; índice de formato do lóculo; espessura do mesocarpo; diâmetro médio da inserção do pedúnculo dos frutos; sólidos solúveis; $\mathrm{pH}$; vitamina $\mathrm{C}$; rendilhamento da casca; e firmeza do fruto. Pode-se concluir que, para o sistema de cultivo em fibra da casca de coco, todos os híbridos são recomendados, exceto o Jab 07\#17, enquanto os híbridos Bônus n 2, Fantasy, Jab 07\#26, Jab $07 \# 28$ e Jab $07 \# 16$ devem ser cultivados em solo.

Termos para indexação: Cucumis melo var. reticulatus, melhoramento, cultivo protegido.

\section{NET MELON EXPERIMENTAL HYBRIDS CULTIVATED IN SOIL AND SUBSTRATE}

\begin{abstract}
This study was carried out to check net melon experimental hybrids performance in two cultivation systems. Six experimental hybrids (Jab 07\#16, Jab 07\#17, Jab 07\#23, Jab 07\#24, Jab 07\#26, and Jab 07\#28) and three commercial hybrids (Bonus $\mathrm{n}^{\circ} 2$, Louis, and Fantasy) were evaluated in two cultivation systems (soil and coconut fiber cultivation). The experimental design used was the randomized blocks, with nine treatments and four replications, and the data analysis was done together. The evaluations were: fruit weight, productivity, transversal fruit diameter, longitudinal fruit diameter, fruit shape index, transversal locule diameter, longitudinal locule diameter, locule shape index, mesocarp thickness, insertion diameter of the stalk's insertion, soluble solids, $\mathrm{pH}$, vitamin $\mathrm{C}$, husk roundness and fruit firmness. Based on the obtained results may be concluded: when the melon was cultivated in coconut fiber all hybrids are recommended, except Jab 07\#17, while Bonus n ${ }^{\circ}$ 2, Fantasy, Jab 07\#26, Jab 07\#28, and Jab 07\#16 hybrids should be cultivated in soil.
\end{abstract}

Index terms: Cucumis melo var. reticulatus; breeding; protected cultivation.

\footnotetext{
${ }^{1}$ (Trabalho 032-10). Recebido em: 19-01-2010. Aceito para publicação em: 28-07-2010.

${ }^{2}$ Engenheiro Agrônomo, DSc. Professor do Instituto Federal de Educação, Ciência e Tecnologia do Triângulo Mineiro (IF Triângulo), Rua João Batista Ribeiro, 4000 - Bairro Mercês - CEP: 38.064-790 Uberaba-MG, e-mail: hamiltoncharlo@iftriangulo.edu.br ${ }^{3}$ Graduanda em Agronomia - Universidade Estadual Paulista (UNESP/FCAV/Câmpus de Jaboticabal), Via de Acesso Prof. Paulo Donato Castellane, s/n, CEP: 14884-900, Jaboticabal-SP, e-mail: francinegalatti@hotmail.com

${ }^{4}$ Engenheira Agrônoma, DSc, Professora Adjunta do Departamento de Produção Vegetal, - Universidade Estadual Paulista (UNESP/FCAV/Câmpus de Jaboticabal), Via de Acesso Prof. Paulo Donato Castellane, s/n, CEP: 14884-900, Jaboticabal-SP, e-mail: leilatb@fcav.unesp.br

${ }_{5}^{5}$ Engenheiro Agrônomo, DSc, Professor Titular do Departamento de Ciências Exatas - Universidade Estadual Paulista (UNESP/ FCAV/Câmpus de Jaboticabal), Via de Acesso Prof. Paulo Donato Castellane, s/n, CEP: 14884-900, Jaboticabal-SP, e-mail: jcbarbosa@fcav.unesp.br
} 


\section{INTRODUÇÃO}

O meloeiro (Cucumis melo) é uma das hortaliças de maior importância econômica no mercado brasileiro, sendo uma das culturas de posição mais uniforme e de maior ascendência nas exportações de hortaliças pelo País. Atualmente, o Brasil está entre os dez maiores produtores de melão no mundo (FAO, 2009).

No Brasil, há o predomínio do cultivo do melão amarelo, porém, nos últimos anos, o cultivo do melão rendilhado tem ganhado destaque, principalmente nos Estados do Paraná e São Paulo, onde tem sido produzido melão rendilhado com sucesso (ROSELATO, 1997; ALVES, 2000). Estes melões apresentam vantagens comerciais em relação aos outros tipos, tais como: preferência pelo consumidor, boa cotação comercial e cultivo em pequenas áreas, com boa lucratividade.

O primeiro cultivo de melão rendilhado no Brasil foi em 1986, pela CAC (Cooperativa Agrícola de Cotia), com sementes importadas do Japão (RIZZO, 2004), sendo que o Brasil ainda importa $100 \%$ das sementes híbridas desta cultura, principalmente dos Estados Unidos e Japão.

No ano de 2008, o Programa de Melhoramento Genético de Melão Rendilhado da UNESPFCAV desenvolveu e avaliou dezenas de híbridos experimentais de melão rendilhado, dos quais seis se destacaram quanto às principais características produtivas e qualitativas, e poderão ser uma opção aos produtores de melão rendilhado.

A utilização de híbridos no cultivo de hortaliças tem possibilitado maior qualidade e produtividade aos produtos. Dentre as vantagens da utilização de híbridos estão a heterose, ou vigor híbrido das plantas, maior uniformidade, precocidade e resistência a doenças e pragas. No geral, plantas híbridas têm sido utilizadas na agricultura e constituem um eficiente recurso para o aumento da produtividade agrícola.

Existe grande potencial de mercado para o melão rendilhado, sobretudo de exportação, com a possibilidade de colocação do produto na entressafra do Hemisfério Norte (dezembro a março). O cultivo do melão rendilhado exige conhecimentos específi$\cos$ do olericultor. Por ser uma cultura relativamente nova no Brasil, existem poucas informações técnicas sobre o assunto. Algumas doenças têm causado sérios problemas, tais como o crestamento gomoso do caule (Didymella bryoniae), Fusarium oxysporum sp. melonis, oídio (Sphaerotheca fuliginea), além do nematoide (Meloydogine incognita), principalmente quando o cultivo é realizado em casa de vegetação, onde geralmente não é feito rotação de culturas ou pousio.

Diante dos problemas fitossanitários enfrentados no cultivo do melão rendilhado em ambiente protegido, têm-se buscado alternativas de cultivo. A principal delas é o cultivo em substratos. Dentre os substratos utilizados na agricultura, a fibra da casca de coco vem apresentando bom desempenho para cultivo de hortaliças, devido à longa durabilidade sem alteração de suas características físicas, pela possibilidade de esterilização, abundância da matéria-prima renovável e baixo custo para o produtor (CARRIJO et al., 2004).

Andriolo et al. (1999) relatam que o cultivo em fibra da casca de coco oferece vantagens, como a redução da ocorrência de problemas fitossanitários, que se traduzem em benefícios diretos na qualidade $\mathrm{e}$ no rendimento dos produtos colhidos, além de facilitar manejo mais adequado de água, fornecimento de nutrientes em doses e épocas apropriadas e redução de salinização do meio radicular.

Diante do exposto, este trabalho teve como objetivo avaliar o desempenho de híbridos experimentais de melão rendilhado em dois sistemas de cultivo.

\section{MATERIAL E MÉTODOS}

O trabalho foi realizado em casa de vegetação, no Setor de Olericultura e Plantas AromáticoMedicinais do Departamento de Produção Vegetal, da Faculdade de Ciências Agrárias e VeterináriasUNESP-Jaboticabal, cujas coordenadas são: $21^{\circ} 15^{\prime} 22^{\prime \prime}$ de latitude sul e $48^{\circ} 18^{\prime} 58^{\prime \prime}$ de longitude oeste, estando à altitude de $614 \mathrm{~m}$. O clima da região é tipo Cwa, baseado na classificação internacional de Köeppen.

As casas de vegetação que abrigaram os experimentos foram do tipo arco, com $50 \mathrm{~m}$ de comprimento, $6 \mathrm{~m}$ de largura, pé-direito de $3,5 \mathrm{~m}$, tela de proteção lateral com sombreamento de $50 \%$ e teto coberto com filme de polietileno de baixa densidade, com 150 micrômetros de espessura.

Os experimentos foram conduzidos em blocos casualizados, com quatro repetições. Foram avaliados os híbridos (Jab 07\#16, Jab 07\#17, Jab 07\#23, Jab 07\#24, Jab 07\#26, Jab 07\#28, desenvolvidos pelo Programa de Melhoramento Genético de Melão Rendilhado da UNESP/Jaboticabal; e Bônus n 2, Louis e Fantasy, considerados padrão de mercado) em dois sistemas de cultivo (solo e fibra da casca de coco).

A semeadura foi realizada em 20 de setembro de 2008, utilizando bandejas de poliestireno 
expandido com 128 células, preenchidas com substratos Plantmax $\mathrm{HT}^{\circledR}$. O transplante para a casa de vegetação foi realizado no dia 03 de outubro de 2008, quando as mudas apresentavam a primeira folha definitiva completamente desenvolvida.

A análise química do solo onde o experimento foi realizado apresentou as seguintes características: $\mathrm{pH}$ em $\mathrm{CaCl}_{2}=6,3 ; \mathrm{MO}=18,0 \mathrm{~g} \mathrm{dm}^{-3} ; \mathrm{P}_{\text {resina }}=54,0$ $\mathrm{mg} \mathrm{dm}{ }^{-3} ; \mathrm{K}=2,8 \mathrm{mmol}_{\mathrm{c}} \mathrm{dm}^{-3} ; \mathrm{Ca}=62,0 \mathrm{mmol}_{\mathrm{c}} \mathrm{dm}^{-}$ 3; $\mathrm{Mg}=30,0 \mathrm{mmol}_{\mathrm{c}} \mathrm{dm}^{-3} ; \mathrm{H}+\mathrm{Al}=22,0 \mathrm{mmol}_{\mathrm{c}} \mathrm{dm}^{-3}$; $\mathrm{SB}=70,1 \mathrm{mmol}_{\mathrm{c}} \mathrm{dm}^{-3} ; \mathrm{T}=99,6 \mathrm{mmol}_{\mathrm{c}} \mathrm{dm}^{-3} ; \mathrm{V} \%=81,0$. A adubação de plantio no sistema em solo foi realizada de acordo com a análise de solo e constou de 30 $\mathrm{kg} \mathrm{ha}^{-1}$ de $\mathrm{N}, 180 \mathrm{~kg} \mathrm{ha}^{-1}$ de $\mathrm{P}_{2} \mathrm{O}_{5}$ e $60 \mathrm{~kg} \mathrm{ha}^{-1} \mathrm{~K}_{2} \mathrm{O}$, fornecidos através de $150 \mathrm{~kg} \mathrm{ha}^{-1}$ de sulfato de amônio, $1.125 \mathrm{~kg} \mathrm{ha}^{-1}$ de superfosfato simples e $103,5 \mathrm{~kg}$ $\mathrm{ha}^{-1}$ de cloreto de potássio, respectivamente. Foram efetuadas quatro adubações em cobertura, sendo a primeira aos 15 dias após o transplante, e as demais em intervalos de 15 dias, totalizando $80 \mathrm{~kg} \mathrm{ha}^{-1}$ de $\mathrm{N}$ e $80 \mathrm{~kg} \mathrm{ha}^{-1} \mathrm{~K}_{2} \mathrm{O}$, através de $400 \mathrm{~kg} \mathrm{ha}^{-1}$ do formulado 20-00-20 (TRANI et al. 1997). As irrigações foram feitas por gotejamento, conforme a necessidade e estádio de desenvolvimento da cultura.

O cultivo do melão em fibra da casca de coco foi realizado em regime de hidroponia aberta, em vasos plásticos, preenchidos com fibra da casca de coco comercial Golden Mix ${ }^{\circledR}$ Misto 98, que possui as seguintes características físicas: porosidade total de $94 \%$, capacidade de aeração de $35 \%$, capacidade de retenção de água disponível 41\% (AMAFIBRA, s.d.). $\mathrm{E}$ as características químicas: $\mathrm{pH} 5,1$; condutividade elétrica - 1,0 dS m${ }^{-1}$; N-nitrato - $8,1 \mathrm{mg} \mathrm{L}^{-1}$; fósforo $53,0 \mathrm{mg} \mathrm{L}^{-1}$; cloreto - 44,6 $\mathrm{mg} \mathrm{L}^{-1}$; enxofre - 92,1 mg $\mathrm{L}^{-1}$; N-amônia - 17,7 mg L-1; potássio - 270,1 mg L-1; sódio - 12,6 mg L-1; cálcio - 9,9 mg L-1; magnésio - 6,6 $\mathrm{mg} \mathrm{L}^{-1}$; boro - $0,5 \mathrm{mg} \mathrm{L}^{-1}$; cobre - $0,1 \mathrm{mg} \mathrm{L}^{-1}$; ferro - 0,4 $\mathrm{mg} \mathrm{L} \mathrm{L}^{-1}$; manganês - $0,1 \mathrm{mg} \mathrm{L}^{-1}$; e zinco - $0,5 \mathrm{mg} \mathrm{L}^{-1}$.

O substrato foi previamente umedecido na proporção de 30 litros de água para cada 100 litros de substrato. Posteriormente, foi realizado o preenchimento dos vasos que continham $31,3 \mathrm{~cm}$ e $22,1 \mathrm{~cm}$ de diâmetro nas partes superior e inferior, respectivamente, $27,5 \mathrm{~cm}$ de altura e capacidade total de $13,0 \mathrm{dm}^{3}$.

Foi utilizada irrigação por gotejamento com solução nutritiva recomendada por Castellane e Araújo (1994), para cultivo hidropônico da cultura, sendo a recomendação de macronutrientes e micronutrientes para 1.000 litros de água a seguinte: $240 \mathrm{~g}$ de sulfato de magnésio; $155 \mathrm{~g}$ de MAP; $805 \mathrm{~g}$ de nitrato de cálcio; $277 \mathrm{~g}$ de nitrato de potássio; $238 \mathrm{~g}$ de cloreto de potássio; e $36 \mathrm{~g}$ de ferro DTPA, $1,8 \mathrm{~g}$ de ácido bórico; $2,54 \mathrm{~g}$ de sulfato de manganês; $1,15 \mathrm{~g}$ de sulfato de zinco; $0,12 \mathrm{~g}$ de sulfato de cobre e $0,12 \mathrm{~g}$ de molibdato de sódio.

A fertirrigação foi controlada por um temporizador, tendo início às 7 horas e término às 18 horas. A lâmina de água aplicada foi definida como a necessária para que ocorresse a drenagem mínima dos vasos, ou seja, fora aplicada a quantidade necessária para que ocorresse o início da drenagem, quando, então, a irrigação era cessada. Do $1^{\circ}$ aos 15 dias após o transplante (DAT), as taxas de aplicação por irrigação foram de $70 \mathrm{~mL}_{\text {hora }}{ }^{-1}$, dos 15 aos 30 DAT foram de $91 \mathrm{~mL} \mathrm{hora}^{-1}$, dos 30 aos 40 DAT foram de $112 \mathrm{~mL} \mathrm{hora}^{-1}$, dos 40 aos 50 DAT foram de $133 \mathrm{~mL}$ hora $^{-1}$, dos 50 aos 60 DAT foram de $168 \mathrm{~mL} \mathrm{hora}^{-1} \mathrm{e}$ dos 60 aos 97 DAT foram de $224 \mathrm{~mL} \mathrm{hora}^{-1}$.

O tutoramento das plantas para os dois sistemas de cultivo foi feito com fitilhos plásticos presos a arames localizados rentes ao solo/vaso e a $2 \mathrm{~m}$ de altura do solo e do vaso. Quando a planta atingiu dois metros de altura, foi realizada a capação. Foram realizadas desbrotas (até o $11^{\circ}$ nó e após a fixação dos frutos) e amarrios das plantas sempre que necessário.

O espaçamento adotado, para ambos os sistemas de cultivo, foi de 1,0 x 0,5 m. Desta forma, cada parcela foi constituída por uma linha de $3,5 \mathrm{~m}$, com sete plantas, sendo considerada como área útil as cinco plantas centrais.

A polinização foi realizada por abelhas acomodadas em colmeias estrategicamente distribuídas na casa de vegetação e, após o pegamento dos frutos, foram efetuados raleios sempre que necessário, para deixar dois frutos por planta. A colheita iniciou-se no dia 05 de janeiro de 2009, estendendo-se até o dia 10 de janeiro de 2009, quando a região de abscisão do pedúnculo apresentava rachadura em todo o seu perímetro.

Em todas as plantas, foram colhidos dois frutos, e, após a colheita, os mesmos foram levados para o Laboratório de Produtos Hortícolas do Departamento de Produção Vegetal, onde foram avaliadas as seguintes características:

a) Massa do fruto: obtida pela razão entre a massa dos frutos da parcela $(\mathrm{kg})$ e o número de frutos da parcela; b) Produtividade: com base na pesagem dos frutos produzidos na parcela útil ( $\mathrm{kg}$ $\mathrm{m}^{-2}$ ); c) Diâmetro transversal e longitudinal do fruto: obtidos por amostragem de cinco frutos, tomados ao acaso em cada parcela, utilizando paquímetro digital e calculando-se a média aritmética $(\mathrm{mm})$; d) Índice de formato de fruto: obtido pela razão entre médias dos diâmetros longitudinal e transversal do fruto; e) Diâmetro transversal e longitudinal do lóculo: obtidos por amostragem de cinco frutos, tomados ao 
acaso em cada parcela, utilizando paquímetro digital e calculando-se a média aritmética (mm); f) Índice de formato do lóculo: obtido pela razão entre médias dos diâmetros longitudinal e transversal do lóculo; g) Espessura do mesocarpo: obtida por amostragem de cinco frutos, tomados ao acaso de cada parcela $(\mathrm{mm})$, utilizando paquímetro digital e calculando-se a média aritmética; h) Diâmetro médio da inserção do pedúnculo dos frutos: obtido pela mensuração da região de inserção de cinco frutos, tomados ao acaso de cada parcela (mm); i) Sólidos solúveis (SS): obtido por meio de refratômetro digital, corrigido a $20^{\circ} \mathrm{C}$, no suco de cinco frutos por parcela, sendo os resultados expressos em ${ }^{\circ} \mathrm{Brix} ; \mathrm{j}$ ) $\mathrm{pH}$ : determinado com suco de uma fatia longitudinal de $5 \mathrm{~cm}$ de espessura, de cinco frutos por parcela, com auxílio de peagâmetro digital; k) Vitamina C: expressa em mg de ácido ascórbico por $100 \mathrm{~mL}$ de suco, obtida através da titulação com 2,6 diclorofenol indofenol de sódio (2,6 DINa); e Rendilhamento da casca: determinada por avaliação visual de acordo com a escala de notas adotada por Rizzo (2004), sendo 1-fraco, 2- médio e 3-intenso; m) Firmeza do fruto: obtido através de um penetrômetro digital, mediante corte transversal em cinco frutos, realizando-se quatro leituras em regiões diferentes e equidistantes, sendo duas para cada parte do fruto, e os resultados convertidos em Newton $(\mathrm{N})$.

Com os dados médios de cada característica avaliada, realizou-se análise de variância. Quando o valor de F calculado foi significativo, realizaram-se comparações entre as médias, pelo teste de Tukey, ao nível de $5 \%$ de probabilidade. Para complementar o estudo, foi realizado análise conjunta dos dados para verificar o melhor sistema de cultivo (substrato ou solo) e o(s) melhor (es) híbrido(s), adotando-se o valor 7 como máximo tolerável para o quociente entre o maior e o menor quadrado médio residual, entre os ensaios, de acordo com Pimentel Gomes (1990). Os cálculos foram realizados utilizando o programa Agroestat (Sistema para Análises Estatísticas de Ensaios Agronômicos), desenvolvido pelo Prof. Dr. José Carlos Barbosa e Walter Maldonado Júnior, UNESP- FCAV, Câmpus de Jaboticabal.

\section{RESULTADOS E DISCUSSÃO}

Na Tabela 1, são apresentadas as médias de massa média dos frutos e produtividade, onde se verifica que ocorreu interação significativa entre híbridos e sistemas de cultivo para essas características. No sistema de cultivo em substrato, observou-se que, para as características de massa média dos frutos e produtividade, apenas o híbrido Jab $07 \# 17(0,63 \mathrm{~kg}$ e $2,52 \mathrm{~kg} \mathrm{~m}^{-2}$ ) diferiu significativamente dos demais, enquanto no solo o híbrido Fantasy se destacou com $1,16 \mathrm{~kg} \mathrm{e} 4,65 \mathrm{~kg} \mathrm{~m}^{-2}$, respectivamente, não diferindo estatisticamente dos genótipos Bônus n ${ }^{\circ} 2$, Jab 07\#26, Jab 07\#28 e Jab 07\#16. Esses resultados são superiores aos verificados por Rizzo e Braz (2001) e Rizzo e Braz (2004) no cultivo em solo e Costa et al. (2003) no cultivo hidropônico (NFT). O desempenho variável entre cultivares comerciais também foi encontrado por Paiva et al. (2000), Rizzo e Braz (2001), Pádua et al. (2003) e Silva et al. (2003). Este comportamento diferencial entre genótipos pode ser explicado pela interação genótipo $\mathrm{x}$ ambiente, que ocorre quando estas plantas são submetidas a diferentes ambientes e respondem de maneira variável.

Vale ressaltar que os híbridos experimentais conduzidos em fibra da casca de coco, exceto o Jab 07\#17, não diferiram dos híbridos comerciais, ou seja, apresentam potencial para exploração comercial e podem ser uma alternativa para os produtores na escolha da cultivar a ser plantada.

Ainda de acordo com a Tabela 1, nota-se que os híbridos Jab 07\#23, Jab 07\#24 e Louis devem ser cultivados preferencialmente em substrato. Gusmão (2001) avaliou a interação genótipo $\mathrm{x}$ ambiente em melão rendilhado e verificou que os genótipos avaliados se comportaram diferentemente de acordo com o sistema de cultivo empregado, sofrendo influência do ambiente. Nerson e Burger (1996) verificaram que linhagens desenvolvidas para o cultivo em campo não produziram híbridos adaptados ao cultivo protegido, indicando a necessidade de um programa de melhoramento exclusivo para o cultivo em determinado ambiente.

Os valores obtidos no presente trabalho são superiores aos observados por Vargas et al. (2008) que, avaliando híbridos de melão rendilhado em dois sistemas de cultivo, verificaram produtividade média de frutos de $3,36 \mathrm{~kg} \mathrm{~m}^{-2}$. Provavelmente, essas diferenças estão relacionadas principalmente à época em que os experimentos foram conduzidos, já que o trabalho mencionado foi conduzido no inverno, e o presente trabalho foi conduzido no verão, época que favorece o desenvolvimento e a produção da cultura. Rizzo e Braz (2004), ao avaliar o desempenho de 20 linhagens de melão rendilhado cultivado em solo, em casa de vegetação, verificaram que a maior massa fresca de fruto foi de $969,6 \mathrm{~g}_{\text {fruto }^{-1}}$, valor inferior ao valor máximo obtido no solo pelo híbrido Jab $07 \# 16$, o que demonstra o seu potencial produtivo.

Araújo (1999) relatou existir uma tendência no mercado interno de consumir frutos com peso próximo de $1 \mathrm{~kg}$, e que, na Europa, existe essa mesma tendência, com exceção da Espanha que tem prefe- 
rência por frutos maiores. Essa tendência existe até hoje, onde frutos de dimensões intermediárias são preferidos, pois podem ser consumidos de uma só vez. Dessa forma, os frutos oriundos do cultivo em substrato seriam os preferenciais, com média de 1,11 kg. Porém, os produzidos em solo, com média 0,95 $\mathrm{kg}$, também apresentam características aceitáveis pelo mercado (Tabela 1).

Na Tabela 2, são apresentadas as médias de diâmetro transversal e longitudinal do fruto e o índice de formato do fruto. Verifica-se que houve interação significativa entre os híbridos e os sistemas de cultivo para as características diâmetro transversal e longitudinal do fruto.

Os híbridos Jab 07\#23 e Jab 07\#24 foram os que apresentaram maior média de diâmetro transversal do fruto quando cultivado em fibra da casca de coco (137,86 e 137,28 mm, respectivamente), diferindo apenas dos híbridos Jab $07 \# 17$ (108,66 $\mathrm{mm})$ e Jab 07\#16 (123,98 mm). No cultivo em solo, não ocorreu diferença significativa entre os híbridos avaliados, sendo a média de $120,60 \mathrm{~mm}$ para esta característica.

Para o diâmetro longitudinal do fruto, os híbridos Jab 07\#26, Jab 07\#23, Jab 07\#28 e Jab 07\#24 foram os que apresentaram maiores médias quando cultivados em fibra da casa de coco, diferindo dos híbridos Fantasy, Jab 07\#17, Jab 07\#16 e Louis. No sistema de cultivo convencional (solo), os híbridos Bônus n²2, Fantasy, Jab 07\#23, Jab 07\#28 e Jab $07 \# 16$ destacaram-se, embora tenham diferido apenas do híbrido Jab 07\#17.

Analisando-se a interação entre híbridos e sistemas de cultivo (Tabela 2), para as características de diâmetro transversal e longitudinal do fruto, sugerese que os híbridos Jab 07\#23, Jab 07\#24 e Louis devam ser cultivados preferencialmente em fibra da casca de coco, enquanto os demais híbridos podem ser cultivados em ambos os sistemas de cultivo, visto que apresentam boa adaptabilidade a ambos os sistemas. Estas características expressam o tamanho do fruto, e a interação entre elas indicam o formato do fruto. Vargas et al. (2008) não verificaram diferenças para essas duas características. Isto ocorreu, provavelmente, pelo número de genótipos avaliados em cada um dos trabalhos, sendo que, no presente estudo, foram avaliados nove genótipos, enquanto no trabalho mencionado foram apenas cinco. Além disso, os referidos autores avaliaram apenas híbridos comerciais, os quais são genótipos que apresentam grande uniformidade, pois são genótipos que já passaram por todas as fases de um processo de seleção.

Quanto ao índice de formato do fruto (Tabela 2), não houve interação entre híbridos e sistemas de cultivo, bem como diferenças entre os sistemas de cultivo. Observaram-se diferenças entre os genótipos, sendo que as médias para esta características, dentre os híbridos, variaram de 0,91 à 1,09 .

Lopes (1982) classifica os frutos de acordo com seu índice de formato, como esféricos (IFF $\cong$ 1), oblongos ( $\mathrm{IFF}=1,1$ a 1,7 ) e cilíndricos (maior que 1,7$)$, no entanto pode-se inferir que frutos com $\mathrm{IFF}<1,0$ resultam em formato mais achatado. Assim, a maioria dos frutos foi classificada como esféricos, exceto o genótipo Jab $07 \# 23$, que possui fruto com formato oblongo, e o Fantasy e Jab 07\#17 com tendência a formato mais achatado. Pádua et al. (2003) afirmam que todos os formatos são aceitos pelo mercado, contudo os esféricos são os mais adequados por permitirem melhor arranjamento nas embalagens utilizadas atualmente.

Na Tabela 3, são apresentadas médias do diâmetro transversal e longitudinal do lóculo e índice de formato do lóculo dos nove híbridos de melão rendilhado avaliados. Verifica-se que houve interação significativa entre híbridos e os sistemas de cultivo apenas para o diâmetro longitudinal do lóculo.

Para o diâmetro transversal do lóculo, observou-se amplitude de 16,1 mm entre os híbridos Jab $07 \# 24(66,51)$ e Jab 07\#17 (50,33). Esses valores estão próximos aos encontrados por Rizzo e Braz (2004), que verificaram diâmetros variando de 50,00 a $66,00 \mathrm{~mm}$. Os híbridos Fantasy $(63,6 \mathrm{~mm})$ e Jab $07 \# 24(66,5 \mathrm{~mm})$ apresentaram as maiores médias, embora não tenham diferido dos híbridos Jab 07\#26, Jab 07\#23, Jab 07\#28, Jab 07\#16 e Louis. No cultivo em fibra da casca de coco, os valores encontrados foram menores que os do solo (Tabela 3). Isso demonstra que o cultivo em substrato proporciona frutos com menor cavidade interna, o que é desejável ao consumidor.

Quanto ao diâmetro longitudinal do lóculo, os híbridos Jab 07\#26, Jab 07\#23 e Jab 07\#16 apresentaram as maiores médias quando cultivados em substrato. Já o híbrido Jab $07 \# 16$ apresentou a maior média para esta característica, quando cultivado em solo. Os demais híbridos não foram influenciados pelo sistema de cultivo para esta característica.

No cultivo em fibra da casca de coco (Tabela 3), os híbridos Jab 07\#26, Jab 07\#23, Jab 07\#28 e $\mathrm{Jab} 07 \# 24$ foram os que apresentaram as maiores médias de diâmetro longitudinal do lóculo, diferindo apenas do híbrido Jab $07 \# 17$ (62,60mm). No solo, o híbrido Jab 07\#16 (85,90 $\mathrm{mm})$ foi o que apresentou maior média, diferindo apenas dos híbridos Jab 07\#23, Jab 07\#17 e Louis. Para frutos de qualidade, desejam-se menores valores de diâmetro longitudinal e transversal do lóculo, pois estes parâmetros indi- 
cam as dimensões da cavidade interna dos frutos, e assim sendo, quanto menor for esta característica, maior será o rendimento de polpa. Os frutos mais desejáveis são os que apresentam menor cavidade interna, pois maior é a tolerância ao transporte e vida útil pós-colheita em relação aos demais genótipos (NUNES et al., 2004).

Observando-se os dados de índice de formato do lóculo, verifica-se que o cultivo em fibra de casca de coco resultou em frutos com maiores valores em relação ao solo. O híbrido Bônus $\mathrm{n}^{\circ} 2$ apresentou maior índice de formato do lóculo com 1,45, diferindo apenas do híbrido Fantasy. Os valores para essa característica variaram de 1,12 a 1,53, com amplitude de $0,41 \mathrm{~mm}$. Estes valores são semelhantes aos relatados por Vargas et al. (2008) para frutos de melão rendilhado.

Para a espessura do mesocarpo não foi detectada interação entre os híbridos e os sistemas de cultivo avaliados (Tabela 4). Também não foram observadas diferenças significativas entre os sistemas de cultivo avaliados, bem como entre os híbridos. Vargas et al. (2008), trabalhando com os híbridos Bônus $n^{\circ}$ 2, Louis e Fantasy, encontraram valores semelhantes. Esta característica, juntamente com os diâmetros longitudinal e transversal do lóculo, permite estimar o rendimento de polpa do fruto, demonstrando maior aproveitamento da parte a ser consumida.

Para o diâmetro de inserção do pedúnculo (Tabela 4), verificou-se que o cultivo em fibra da casca de coco apresentou maior média quando comparada ao cultivo em solo. Para o fator híbridos, não se verificou diferença significativa para esta característica.

Quanto aos sólidos solúveis (Tabela 5), o cultivo em fibra da casca de coco resultou em valores superiores ao solo, sendo que o híbrido Bônus $\mathrm{n}^{\circ} 2$ $\left(12,05{ }^{\circ} \mathrm{Brix}\right)$ obteve a maior média, não diferindo de Jab 07\#17, Jab 07\#16 e Louis. Esses valores são significativos, uma vez que a qualidade do fruto do meloeiro está estreitamente relacionada aos teores de sólidos solúveis. Castoldi et al. (2008), em estudos com cinco híbridos de melão rendilhado, observaram valores de sólidos solúveis variando entre 9,00 e $11,24^{\circ}$ Brix. Portanto, as médias de desempenho encontradas no presente trabalho são semelhantes aos valores verificados pelos autores acima citados.

Alves (2000) considera que frutos com, no mínimo, $10^{\circ}$ Brix podem ser destinados à exportação. De acordo com a classificação proposta por Gorgatti Neto et al. (1994), frutos do híbrido Bônus $n^{\circ} 2$ podem ser classificados como extras por apresentarem mais que $12{ }^{\circ}$ Brix. Vários fatores ambientais ou relacionados com o ambiente são capazes de influen- ciar no teor de sólidos solúveis dos frutos, incluindo reguladores de crescimento, fertilizantes, micronutrientes, temperatura e intensidade luminosa, área foliar e estágio de maturação (SILVA et al., 2002). O acúmulo de sólidos solúveis está relacionado diretamente com a translocação de solutos provenientes da fotossíntese; dessa forma, o desenvolvimento vegetativo próximo ao fruto interfere diretamente nesta qualidade. A posição do fruto com relação à planta é um dos principais manejos ligado à cultura para proporcionar maiores teores nos frutos. Segundo Brandão Filho e Vasconcelos (1998), ao deixar o fruto no entrenó mais próximo da base da planta, haverá maiores quantidades de folhas acima, favorecendo assim a produção de sólidos solúveis, o contrário ocorre quando se deixa o fruto em entrenó muito acima, sendo o ideal balancear a mesma quantidade de folhas tanto acima quanto abaixo dos frutos.

Quanto ao $\mathrm{pH}$, verificou-se que os sistemas de cultivo não apresentaram diferença significativa entre si. O genótipo Jab 07\#17 apresentou maior média $(6,10)$ (Tabela 5). Castoldi et al. (2008) verificaram que os híbridos Fantasy, Bônus n 2 e Louis apresentaram valores de 6,$54 ; 6,52$ e 6,43 , respectivamente. $\mathrm{O}$ teor de $\mathrm{pH}$ pode indicar o ponto de maturação do fruto, e assim estimar a precocidade. Segundo Chitarra e Chitarra (2005), a acidez dos frutos, geralmente, tende a decrescer devido à utilização dos ácidos orgânicos na atividade respiratória, que é intensa à medida que segue o crescimento e a maturação dos frutos. Para Lehninger et al. (2002), o ácido cítrico, que inicia as reações do Ciclo de Krebs, e outros ácidos orgânicos utilizados como intermediários nas reações podem ter seus valores reduzidos na polpa.

Quanto à vitamina C (Tabela 5), o cultivo em solo resultou em frutos com maior média que em relação à do substrato. Verificou-se que o híbrido Bônus $n^{\circ} 2$ apresentou superioridade nos resultados, com média de $42,61 \mathrm{mg}$ de ácido ascórbico $100 \mathrm{~mL}^{-1}$ de suco.

Com resultados semelhantes aos observados por Vargas (2008), verificou-se, no presente trabalho, que para a característica de firmeza da polpa do fruto (Tabela 6), tanto para cultivo em substrato como para solo, o genótipo Jab 07\#17 apresentou a maior média. Portanto, este genótipo apresenta polpa mais firme. Os frutos com polpa menos firmes foram o Fantasy e o Jab 07\#26. Essa característica é de grande importância, pois frutos com maior firmeza de polpa possuem maior resistência ao transporte, manuseio e vida de prateleira.

Para o rendilhamento da casca (Tabela 6), característica importante nesse tipo de melão, verificouse que os genótipos Bônus n $n^{\circ} 2$ e Fantasy, devem ser 
preferencialmente cultivados em fibra de coco, pois apresentaram maior rendilhamento que no solo; Já os híbridos Jab $07 \# 26$ e Jab 07\#23 apreentaram maior rendilhamento quando cultivados no solo, enquanto os demais híbridos independem do sistema de cultivo para expressar seu rendilhamento. No cultivo em fibra da casca de coco, os híbridos mais rendilhados foram Bônus n 2, Fantasy, Jab 07\#26, Jab 07\#17, Jab
07\#24, Jab 07\#16 e Louis. Castoldi et al. (2008), ao avaliarem híbridos comerciais de melão rendilhado, verificaram rendilhamento variando de médio à intenso, o que corrobora os dados do presente estudo. A aparência externa do fruto de melão é um atributo de qualidade, e comercialmente desejam-se melões com alta intensidade de rendilhamento, já que este se torna atrativo ao consumidor.

TABELA 1-Massa média dos frutos (MMF) e Produtividade (P) de híbridos de melão rendilhado em função dos sistemas de cultivo (fibra da casca de coco e solo). UNESP - FCAV, Jaboticabal-SP, 2010.

\begin{tabular}{|c|c|c|c|c|c|c|c|c|c|c|c|c|c|c|}
\hline \multirow{2}{*}{ HÍBRIDOS } & \multicolumn{7}{|c|}{ MMF (kg) } & \multicolumn{7}{|c|}{$P\left(\mathrm{~kg} \mathrm{~m}^{-2}\right)$} \\
\hline & \multicolumn{2}{|l|}{ Fibra } & \multicolumn{2}{|l|}{ Solo } & \multicolumn{2}{|l|}{ Média } & Teste $\mathrm{F}$ & Fibra & \multicolumn{2}{|r|}{ Solo } & 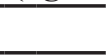 & \multicolumn{2}{|l|}{ Média } & Teste $\mathrm{F}$ \\
\hline Bônus $n^{\circ} 2$ & 1,14 & $\mathrm{Aa}$ & 0,99 & Aabc & 1,06 & $\mathrm{a}$ & $2,53^{\mathrm{NS}}$ & 4,55 & $\mathrm{Aa}$ & 3,97 & Aabc & 4,26 & $\mathrm{a}$ & $2,53^{\mathrm{NS}}$ \\
\hline Fantasy & 1,26 & $\mathrm{Aa}$ & 1,16 & $\mathrm{Aa}$ & 1,21 & $\mathrm{a}$ & $1,19^{\mathrm{NS}}$ & 4,05 & Aa & 4,65 & $\mathrm{Aa}$ & 4,85 & $\mathrm{a}$ & $1,19^{\mathrm{NS}}$ \\
\hline Louis & 1,09 & $\mathrm{Aa}$ & 0,85 & Bcd & 0,97 & $\mathrm{a}$ & $7,20 * *$ & 4,37 & Aa & 3,4 & Bcd & 3,88 & $\mathrm{a}$ & $7,20 * *$ \\
\hline $\mathrm{Jab} 07 \# 16$ & 1,02 & $\mathrm{Aa}$ & 1,15 & $\mathrm{Aab}$ & 1,09 & $\mathrm{a}$ & $1,93^{\mathrm{NS}}$ & 4,09 & $\mathrm{Aa}$ & 4,59 & Aab & 4,34 & $\mathrm{a}$ & $1,93^{\mathrm{NS}}$ \\
\hline Jab $07 \# 17$ & 0,63 & $\mathrm{Ab}$ & 0,92 & Abcd & 0,67 & $\mathrm{a}$ & $0,98^{\mathrm{NS}}$ & 2,52 & $\mathrm{Ab}$ & 2,86 & Ad & 2,69 & $\mathrm{a}$ & $0,89^{\mathrm{NS}}$ \\
\hline $\mathrm{Jab} 07 \# 23$ & 1,34 & $\mathrm{Aa}$ & 0,92 & Bbcd & 1,13 & $\mathrm{a}$ & $20,73 * *$ & 5,36 & $\mathrm{Aa}$ & 3,70 & Bbcd & 4,53 & $\mathrm{a}$ & $20,73^{* *}$ \\
\hline Jab 07\#24 & 1,34 & $\mathrm{Aa}$ & 0,91 & Bcd & 1,13 & $\mathrm{a}$ & $22,13 * *$ & 5,37 & Aa & 3,65 & Bcd & 4,51 & $\mathrm{a}$ & $22,13 * *$ \\
\hline Jab 07\#26 & 1,11 & Aa & 0,94 & Aabcd & 1,02 & $\mathrm{a}$ & $3,45^{\mathrm{NS}}$ & 4,42 & $\mathrm{Aa}$ & 3,74 & Aabcd & 4,08 & $\mathrm{a}$ & $3,45^{\mathrm{NS}}$ \\
\hline $\mathrm{Jab} 07 \# 28$ & 1,07 & $\mathrm{Aa}$ & 0,95 & Aabc & 1,01 & $\mathrm{a}$ & $2,19^{\mathrm{NS}}$ & 4,33 & Aa & 3,79 & Aabc & 4,06 & $\mathrm{a}$ & $2,19^{\mathrm{NS}}$ \\
\hline Média & 1,11 & A & 0,95 & B & & & & 4,45 & A & 3,82 & $\mathrm{~B}$ & & & \\
\hline Teste F & $7,65^{* *}$ & & $8,48^{*}$ & & & & & $7,65^{*}$ & & $8,48^{*}$ & & & & \\
\hline \multirow[t]{2}{*}{$\mathrm{CV}(\%)$} & 13,97 & & 9,97 & & & & & 13,97 & & 9,97 & & & & \\
\hline & \multicolumn{5}{|c|}{$\mathrm{SC} \times \mathrm{H}=4,39 * *$} & & & \multicolumn{6}{|c|}{$\mathrm{SC} \times \mathrm{H}=4,39^{* *}$} & \\
\hline
\end{tabular}

Médias seguidas de mesma letra, maiúscula na linha e minúscula na coluna, não diferem entre si, pelo teste de Tukey, a 5\% de probabilidade.

$*, * * \mathrm{e}^{\text {ns }}$, significativo ao nível de $1 \%$ de probabilidade, significativo ao nível de $1 \%$ de probabilidade e não significativo pelo teste $\mathrm{F}$, respectivamente. 


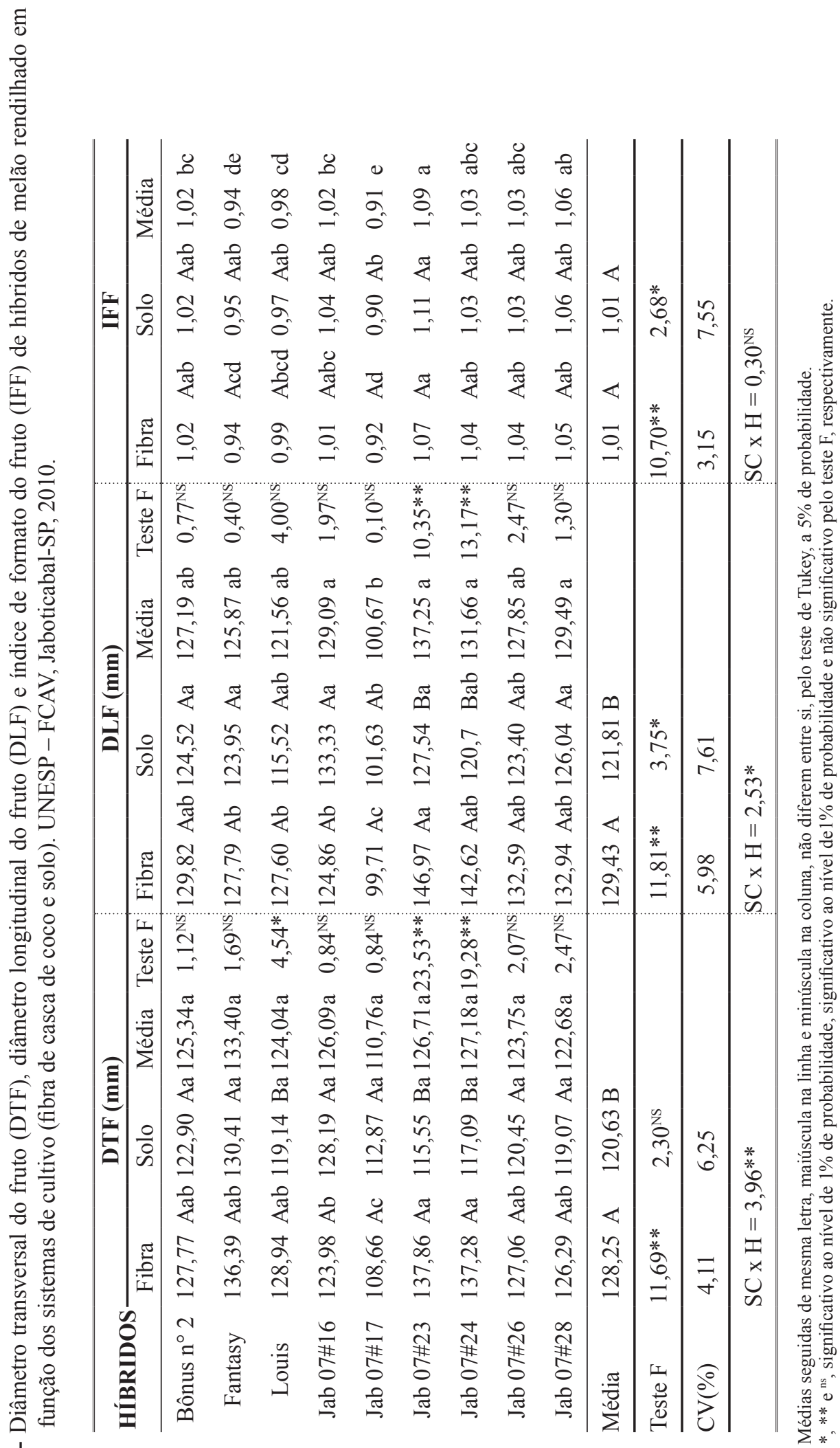

虫 


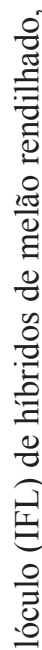


TABELA 4 - Médias da espessura do mesocarpo (EM) e do diâmetro de inserção do pedúnculo (DIP), de híbridos de melão rendilhado, em função dos sistemas de cultivo (fibra de casca de coco e solo). UNESP - FCAV, Jaboticabal-SP, 2010.

\begin{tabular}{|c|c|c|c|c|c|c|c|c|c|}
\hline \multirow{2}{*}{ HÍBRIDOS } & \multicolumn{4}{|c|}{ EM (mm) } & \multicolumn{5}{|c|}{ DIP (mm) } \\
\hline & Fibra & & Solo & Média & Fibra & & Solo & & Média \\
\hline Bônus $n^{\circ} 2$ & 35,39 & $\mathrm{Aa}$ & $33,65 \mathrm{Aa}$ & $34,52 \mathrm{a}$ & 10,32 & $\mathrm{Aa}$ & 6,21 & $\mathrm{Aa}$ & $8,27 \mathrm{a}$ \\
\hline Fantasy & 33,79 & $\mathrm{Aab}$ & $31,31 \mathrm{Aa}$ & $32,55 \mathrm{a}$ & 9,18 & Aabc & 6,47 & $\mathrm{Aa}$ & $7,82 \mathrm{a}$ \\
\hline Louis & 32,48 & $\mathrm{Aab}$ & $30,64 \mathrm{Aa}$ & $31,56 \mathrm{a}$ & 9,36 & Aabc & 7,30 & $\mathrm{Aa}$ & $8,33 a$ \\
\hline Jab $07 \# 16$ & 31,81 & $\mathrm{Aab}$ & $34,31 \mathrm{Aa}$ & $33,06 \mathrm{a}$ & 9,37 & Aabc & 6,59 & $\mathrm{Aa}$ & $7,98 \mathrm{a}$ \\
\hline Jab $07 \# 17$ & 30,48 & $\mathrm{Aab}$ & $27,58 \mathrm{Aa}$ & $29,02 \mathrm{a}$ & 9,87 & $\mathrm{Aab}$ & 7,07 & $\mathrm{Aa}$ & $8,47 a$ \\
\hline Jab $07 \# 23$ & 31,32 & Aab & $33,98 \mathrm{Aa}$ & $32,65 \mathrm{a}$ & 9,27 & Aabc & 6,76 & $\mathrm{Aa}$ & $8,01 \mathrm{a}$ \\
\hline Jab 07\#24 & 33,79 & $\mathrm{Aab}$ & $30,27 \mathrm{Aa}$ & $32,03 \mathrm{a}$ & 7,65 & $\mathrm{Abc}$ & 4,73 & $\mathrm{Aa}$ & $6,19 a$ \\
\hline $\mathrm{Jab} 07 \# 26$ & 29,48 & $\mathrm{Ab}$ & $30,51 \mathrm{Aa}$ & $29,99 a$ & 7,45 & $\mathrm{Ac}$ & 5,22 & $\mathrm{Aa}$ & $6,33 a$ \\
\hline $\mathrm{Jab} 07 \# 28$ & 32,04 & $\mathrm{Aab}$ & $30,81 \mathrm{Aa}$ & $31,42 \mathrm{a}$ & 7,80 & $\mathrm{Abc}$ & 7,25 & $\mathrm{Aa}$ & $7,52 \mathrm{a}$ \\
\hline Média & 32,28 & $\mathrm{~A}$ & $31,45 \mathrm{~A}$ & & 8,92 & $\mathrm{~A}$ & 6,40 & $\mathrm{~B}$ & \\
\hline Teste F & $2,27^{* *}$ & & $2,01^{\mathrm{NS}}$ & & $4,79 * *$ & & $2,57^{\mathrm{NS}}$ & & \\
\hline \multirow[t]{2}{*}{$\mathrm{CV}(\%)$} & 7,49 & & 9,73 & & 10,55 & & 17,40 & & \\
\hline & \multicolumn{4}{|c|}{$\mathrm{SC} \times \mathrm{H}=1,41^{\mathrm{NS}}$} & \multicolumn{5}{|c|}{$\mathrm{SC} \times \mathrm{H}=1,66^{\mathrm{NS}}$} \\
\hline
\end{tabular}

Médias seguidas de mesma letra, maiúscula na linha e minúscula na coluna, não diferem entre si, pelo teste de Tukey, a 5\% de probabilidade.

*, $* *$ e ns , significativo ao nível de $1 \%$ de probabilidade, significativo ao nível de $1 \%$ de probabilidade e não significativo pelo teste $\mathrm{F}$, respectivamente. 
¿

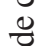

ฮี

\&

营

$\stackrel{2}{2}$

0

:

on

䓛

范

0
0
0
0
0
0
0
0
20
0
0
0
0
0
0
0
0
0
0
0
0
0

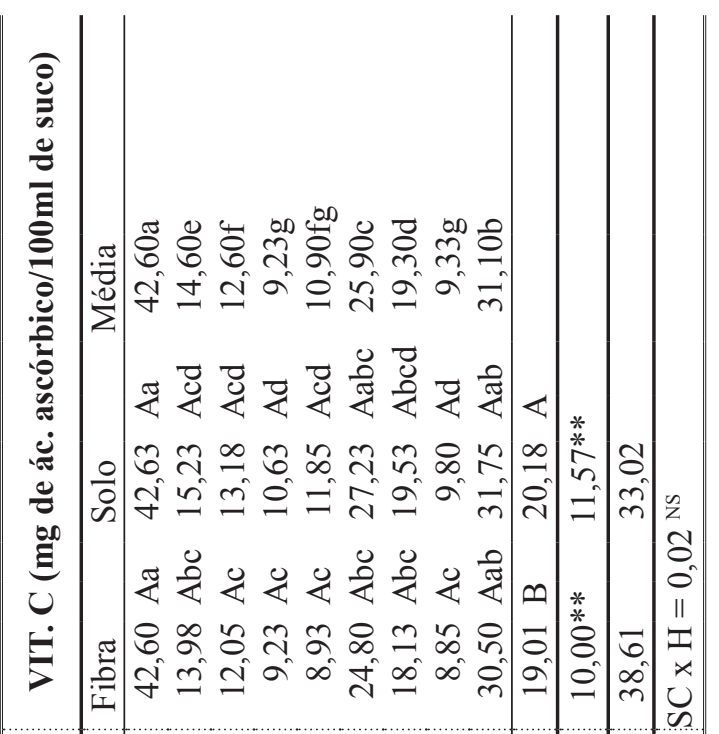

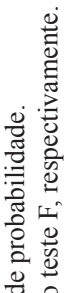

응

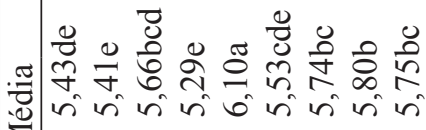

- |

플

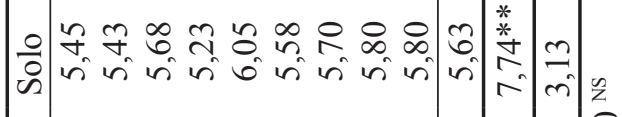

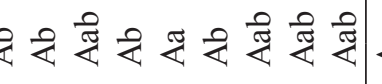

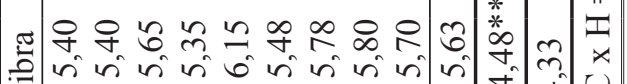

‥

当.

$\frac{8}{5}$

苞 话

율

की:

言

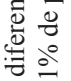

疍

害常

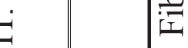

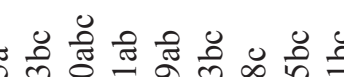

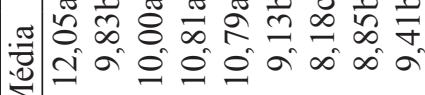

ํㅗㅇ

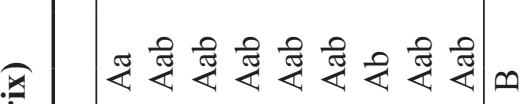

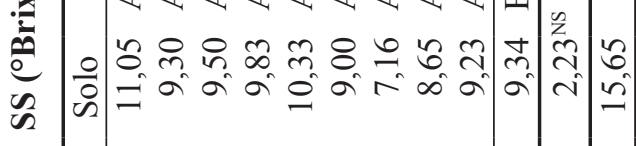

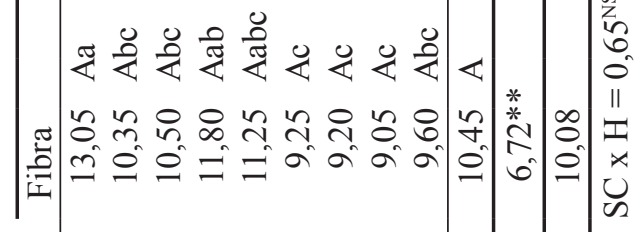

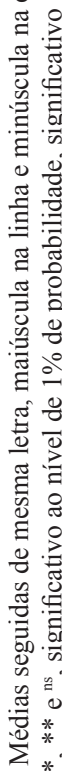

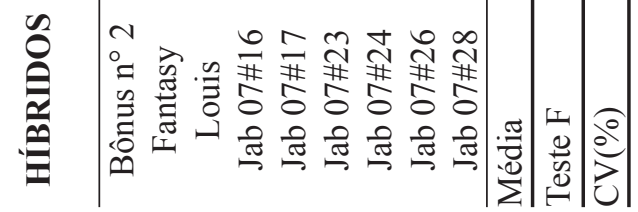


TABELA 6 - Médias de firmeza do fruto e rendilhamento da casca de híbridos de melão rendilhado em função dos sistemas de cultivo (fibra de casca de coco e solo). UNESP - FCAV, Jaboticabal-SP, 2010.

\begin{tabular}{|c|c|c|c|c|c|c|c|c|}
\hline \multirow{2}{*}{ HÍBRIDOS } & \multicolumn{4}{|c|}{ FIRMEZA DA POLPA } & \multicolumn{4}{|c|}{ RENDILHAMENTO } \\
\hline & Fibra & & Solo & Média & Fibra & Solo & Média & Teste F \\
\hline Bônus $n^{\circ} 2$ & 15,70 & $\mathrm{Abc}$ & 15,10 Acd & $15,40 \mathrm{~cd}$ & $3,00 \mathrm{Aa}$ & 2,62 Babc & $2,81 \mathrm{a}$ & $5,19 *$ \\
\hline Fantasy & 13,40 & Ac & $12,90 \mathrm{Ad}$ & $13,00 \mathrm{e}$ & 2,75 Aabc & $2,37 \mathrm{Bc}$ & $2,56 \mathrm{a}$ & $5,00 *$ \\
\hline Louis & 16,10 & $\mathrm{Abc}$ & 17,20 Abcd & $16,60 \mathrm{c}$ & 3,00 Aa & $3,00 \mathrm{Aa}$ & $3,00 \mathrm{a}$ & $0,00^{\mathrm{NS}}$ \\
\hline Jab $07 \# 16$ & 15,90 & $\mathrm{Abc}$ & 16,40 Abcd & $16,20 \mathrm{~cd}$ & 2,50 Aabc & 2,83 Aabc & $2,66 a$ & $3,72^{\mathrm{NS}}$ \\
\hline Jab $07 \# 17$ & 27,30 & Ac & $27,00 \mathrm{Aa}$ & $27,10 \mathrm{a}$ & $3,00 \mathrm{Aa}$ & 2,91 Aabc & $2,96 a$ & $0,27^{\mathrm{NS}}$ \\
\hline Jab $07 \# 23$ & 22,40 & $\mathrm{Aab}$ & $23,70 \mathrm{Aab}$ & $23,00 \mathrm{~b}$ & $2,38 \mathrm{Bbc}$ & 2,94 Aabc & $2,66 \mathrm{a}$ & $11,14 * *$ \\
\hline Jab $07 \# 24$ & 15,70 & $\mathrm{Abc}$ & 16,10 Abcd & $15,90 \mathrm{~cd}$ & 2,88 Aab & $3,00 \mathrm{Aa}$ & $2,94 a$ & $0,55^{\mathrm{NS}}$ \\
\hline Jab $07 \# 26$ & 14,40 & $\mathrm{Abc}$ & 14,90 Acd & $14,70 \mathrm{de}$ & 2,69 Babc & $3,00 \mathrm{Aa}$ & $2,93 a$ & $8,19 * *$ \\
\hline $\mathrm{Jab} 07 \# 28$ & 21,50 & $A a b$ & 21,40 Aabc & $21,40 \mathrm{~b}$ & 2,31 Ac & $2,46 \mathrm{Abc}$ & $2,39 a$ & $0,74^{\mathrm{NS}}$ \\
\hline Média & 18,00 & $\mathrm{~A}$ & $18,30 \mathrm{~A}$ & & $2,72 \quad \mathrm{~A}$ & $2,81 \mathrm{~A}$ & & \\
\hline Teste F & $7,57 * *$ & & $8,92 * *$ & & $5,99 * *$ & $4,55 * *$ & & \\
\hline \multirow[t]{2}{*}{$\overline{\mathrm{CV}(\%)}$} & 18,60 & & 17,14 & & 8,18 & 9,00 & & \\
\hline & \multicolumn{4}{|c|}{$\mathrm{SC} \times \mathrm{H}=0,08^{\mathrm{NS}}$} & \multicolumn{4}{|c|}{$\mathrm{SC} \times \mathrm{H}=4,04 * *$} \\
\hline
\end{tabular}

Médias seguidas de mesma letra, maiúscula na linha e minúscula na coluna, não diferem entre si, pelo teste de Tukey, a 5\% de probabilidade.

$*, * * \mathrm{e}^{\text {ns }}$, significativo ao nível de $1 \%$ de probabilidade, significativo ao nível de $1 \%$ de probabilidade e não significativo pelo teste $\mathrm{F}$, respectivamente.

\section{CONCLUSÃO}

Pode-se concluir que, para o sistema de cultivo em fibra da casca de coco, todos os híbridos são recomendados, exceto o Jab 07\#17, enquanto os híbridos Bônus n², Fantasy, Jab 07\#26, Jab 07\#28 e Jab $07 \# 16$ também podem ser cultivados no sistema convencional - solo.

\section{AGRADECIMENTOS}

Agradecemos à Fundação de Amparo à Pesquisa do Estado de São Paulo (FAPESP), pela concessão do auxílio à pesquisa, processo $n^{\circ} 08 / 51229$ 0 , e pela bolsa de doutorado ao primeiro autor do trabalho, processo $\mathrm{n}^{\circ}$ 2007/59043-0.

\section{REFERÊNCIAS}

ALVES, R. E. Melão: pós-colheita. Brasília: Embrapa Comunicação para Transferência de Tecnologia, 2000. 43 p. (Frutas do Brasil, 10).

AMAFIBRA. FIBRAS E SUBSTRATOS AGRÍCOLAS DA AMAZÔNIA. Fibra de coco. Campinas: Holambra.

ANDRIOLO, J. L.; DUARTE,T. S.; LUDKE, T.; SKREBSKY, E. C. Caracterização e avaliação de substratos para cultivo do tomateiro fora do solo. Horticultura Brasileira, Brasília, v.17, n. 3, p. 215-219, 1999.
ARAÚJO, J. L. P. Evaluación de la calidad comercial y posibilidades de mercado del melón brasileño comercizable en Europa. 1999. 285 f. Tese (Doutorado)- Universidade de Córdoba, Córdoba, 1999.

BRANDÃO FILHO, J. U. T.; VASCONCELLOS, M. A. S. A cultura do meloeiro. In: GOTO, R.; TIVELLI, S. W. Produção de hortaliças em ambiente protegido: condições subtropicais. São Paulo: Editora UNESP, 1998. p.161-194.

CARRIJO, O. A.; VIDAL, M. C.; REIS, N. V. B.; SOUZA, R. B.; MAKISHIMA, N. Produtividade do tomateiro em diferentes substratos e modelos de casas de vegetação. Horticultura Brasileira, Brasília, v. 22 , n. 1, p. 5-9, 2004.

CASTEllane, P. D.; ARAÚJO, J. A. C. Cultivo sem solo: hidroponia. Jaboticabal: FUNEP, 1994. $43 \mathrm{p}$.

CASTOLDI, R.; CHARLO, H. C. O.; VARGAS, P. F.; BRAZ, L. T. Qualidade de frutos de cinco híbridos de melão rendilhado em função do número de frutos por planta. Revista Brasileira de Fruticultura, Jaboticabal, v. 30, n. 2, p. 455-458, 2008.

Chitarra, M. I. F.; CHITARRA, A. B. Pós-colheita de frutos e hortaliças: fisiologia e manuseio. Lavras: UFLA, 2005. 783 p. 
COSTA, C. C.; CECÍLIO FILHO, A. B.; CAVARIANNI, R. L.; BARBOSA, J. C. Produção do melão rendilhado em função da concentração de potássio na solução nutritiva e do número de frutos por planta. Horticultura Brasileira, Brasília, v. 22, n. 1, p. 23-27, 2003.

FAO. Food and Agriculture Organization of the United Nations. Faoestat. Disponível em: $<$ http:// faostat.fao.org/site/339/default.aspx $>$. Acesso em: 5 out. 2009 .

GORGATTI NETO, A. ; GAYET, J. P.; BEINROTN, E. W.; MATALLO, M.; GARCIA, E. E. C.; GARCIA, A. E.; ARDITO, G. F. G.; BORDIN, M. R. Melão para exportação: procedimento de colheita e póscolheita. Brasília: Embrapa-SPI/Frupex, 1994. 37 p. (Publicações Técnicas, 6).

GUSMÃO, S. A. L. Interação genótipo x ambiente em híbridos de melão rendilhado (Cucumis melo var. reticulatus Naud.). 2001. 143 f. Tese (Doutorado em Agronomia) - Faculdade de Ciências Agrárias e Veterinárias, Universidade Estadual Paulista, Jaboticabal, 2001.

LEHNINGER, A. L.; NELSON, D. L.; COX, M. M. Princípios de bioquímica. 2. ed. São Paulo: Savier, 2002. $1292 \mathrm{p}$.

LOPES, J. F. Melhoramento genético (chuchu, melancia, melão e pepino). Informe Agropecuário, Belo Horizonte, v. 8, n. 85, p. 61-64, 1982.

NERSON, H.; BURGUER, Y. Parental characteristics limit yield and quality of winter-grown galiatype muskmelon. Journal of Genetics \& Breeding, Rome, v. 50, n. 1, p. 61-66, 1996.

NUNES, G. H. S.; SANTOS JÚNIOR, J. J. S.; VALE, F. A.; BEZERRA NETO, F.; ALMEIDA, A. H. B.; MEDEIROS, D. C. Aspectos produtivos e de qualidade de híbridos de melão cultivados no agropolo Mossoró-Assu. Horticultura Brasileira, Brasília, v. 22, n. 4, p. 744-747, 2004.

PÁDUA, J. G.; BRAZ, L.T.; BANZATTO, D. A.; GUSMÃO, S. A. L. Net melon productivity under different cultivation systems, during summer and winter. Acta Horticulturae, Piracicaba, v. 607, n.1, p. 83-89, 2003.

PAIVA, W. O.; HASSAN NETO, S.; LOPES, A. G. S. Avaliação de linhagens de melão. Horticultura Brasileira, Brasília, v. 18, n. 2, p. 109-113, 2000.
PIMENTEL GOMES, F. Curso de estatística experimental. 13. ed. Piracicaba: Nobel, 1990. 647 p.

RIZZO, A. A. N. Obtenção e avaliação de genótipos de melão rendilhado em ambiente protegido. 2004. 38 f. Tese (Doutorado em Agronomia - Área de Concentração em Produção Vegetal) - Faculdade de Ciências Agrárias e Veterinárias, Universidade Estadual Paulista, Jaboticabal, 2004.

RIZZO, A. A. N.; BRAZ, L. T. Características de cultivares de melão rendilhado cultivadas em casa de vegetação. Horticultura Brasileira, Brasília, v. 19 , n. 3, p. 370-373, 2001

RIZZO, A. A. N.; BRAZ, L. T. Desempenho de linhagens de melão rendilhado em casa de vegetação. Horticultura Brasileira, Brasília, v. 22, n.4, p. 784-788, 2004.

ROSELATO, C. Melão-de-renda é nova opção para estufas. Suplemento Agrícola, São Paulo, n. 2187, p. 3, 1997.

SILVA, P. S. L.; MARIGUELE, K. H. ; SILVA, P. I. B. Produtividade do meloeiro em função de cultivares e épocas de semeadura. Revista Brasileira de Fruticultura, Jaboticabal, v. 25, n. 3, p. 552-554, 2003.

SILVA, P. S. L.; SÁ, W. R.; MARIGUELE, K. H.; BARBOSA, A. P. R.; OLIVEIRA, O. F. Distribuição do teor de sólidos solúveis totais em frutos de algumas espécies de clima temperado. Revista Caatinga, Mossoró, v. 15, n. 1, p. 19-23, 2002.

TRANI, P. E.; PASSOS, F. A.; NAGAI, H.; MELO, A. M. T. Melão e melancia. In: RAIJ, B. van; CANTARELLA, J. A.; QUAGGIO, R.; FURLANI, A. M. C. (Ed.). Recomendação de adubação e calagem para o Estado de São Paulo. 2. ed. Campinas: IAC, 1997. $285 \mathrm{p}$

VARGAS, P. F. Estudo da heterose e da capacidade combinatória em híbridos de melão rendilhado. 2008. 98 f. Dissertação (Mestrado em Agronomia) - Faculdade de Ciências Agrárias e Veterinárias, Universidade Estadual Paulista, Jaboticabal, 2008.

VARGAS, P. F.; CASTOLDI, R.; CHARLO, H. C. O.; BRAZ, L. T. Desempenho de cultivares de melão rendilhado em função do sistema de cultivo. Horticultura Brasileira, Brasília, v. 26, n. 2, p. 197-201, 2008. 